\title{
Occupational Health Problems of Construction Workers in Valley of Kashmir
}

\author{
Mohammad Sarwar Mir ${ }^{1 *}$, Ruksana Hamid², Mohammad Azhar ${ }^{3}$ and Ghulam Mustafa Malik ${ }^{4}$ \\ ${ }^{1}$ Senior Resident, Department of Hospital Administration, India \\ ${ }^{2}$ Medical Officer and Anesthesiologist, India \\ ${ }^{3}$ Casualty Medical Officer, SKIMS MC, India \\ ${ }^{4}$ DNB Ophthalmology Resident, India
}

*Corresponding author: Mohammad Sarwar Mir, Senior Resident, Department of Hospital Administration, SKIMS

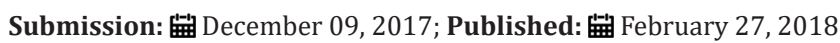

\begin{abstract}
Occupational risks have been classed as the tenth leading cause of morbidity and mortality and occupational skin diseases are important problem in the construction industries.
\end{abstract}

Aim: The aim of this study is to understand the occupational health problems of construction workers engaged at large construction site in Kashmir

Materials and methods: The cross-sectional study was conducted at a large scale construction site of a cement factory on outskirts of Srinagar. All workers $(\mathrm{N}=200)$ were enrolled as study subjects. Data was collected by the team consisting of investigators, doctors and social worker using a pre tested validated structured proforma.

Result: Among 200 workers only $28.0 \%$ used protective measure and $70 \%$ had suffered with at least one form of disease. Among them different diseases were found in following percentages i.e. respiratory problems (45.7\%), musculo skelekal problems (32.8\%), dermatitis (78.6\%), burn/scald $(6.6 \%)$ and accidental injury $(28.6 \%)$

Conclusions: Measures are needed to improve the work environment of construction workers by ensuring availability of protective gears, sanitation facilities at the sites along with an accessible, accountable occupational health services.

Keywords: Building and construction workers; Occupational health; Skin problems; Work related injury

\section{Introduction}

The construction industry is one of the world's major industries. It is an essential contributor to the process of development. Being an unorganized sector the workforce is at risk of developing safety and health related hazards at work [1].

Construction workers in both are at a greater risk of developing certain health disorders and sickness than workers in many other industries. They are exposed to multiple physical, chemical and biological agents, which make them vulnerable to various health problems that include-injuries, respiratory problems, dermatitis, musculo-skeletal disorders and gastro-intestinal diseases. The work is hard physical labor, often under difficult conditions like adverse weather conditions and the nature of work, hours of work, low pay, poor living conditions with lack of basic amenities and separation from family, lack of job security and lack of access to occupational health services make the situation worse. Due to ergonomic issues they are also vulnerable to degenerative disorders. Apart from this, in most of construction projects the workers employed are unorganized in nature and often not guided by the legislations made for the health and welfare of the workers and hence are not eligible for free or subsidized care [2].

In the era of globalization construction is a fast growing industry and very little research has been done on the occupational health, hazards and psychosocial problems of these workers especially in Kashmir. In this context to understand the health problems of construction workers and advocate public health policy measures, this study was conducted $[3,4]$. Objectives

a) To study health problems of construction workers at a large construction site.

b) To suggest measures for improvement of health of these workers.

\section{Material and Method}

A cross sectional study was conducted at a large construction site in Srinagar in May 2014. All the 200 construction workers 
working at the site in were selected. After a complete physical examination, data were recorded in a pre-designed structured questionnaire, providing a detailed job condition, personal and past medical history and the length of employment in the current job position. The duration of exposure was calculated as years in occupation. In addition, the subjects were asked about their personal work habits, use of protective equipments and the type of personal protective equipment used. All collected data were checked and rechecked for omissions, inconsistencies and improbabilities. Data analysis were performed by Statistical Package for Social Science (SPSS), version-17. Prevalence, percentage, mean and median were calculated.

\section{Result}

A total of two hundred workers were studied during the research period (Table 1-5).

Table 1: Age wise distribution $(\mathrm{n}=200)$.

\begin{tabular}{|c|c|c|}
\hline Age & Frequency & Percentage \\
\hline$<18$ & 20 & 10 \\
\hline $18-45$ & 136 & 68 \\
\hline$>45$ & 44 & 22 \\
\hline
\end{tabular}

Table 2: Duration of work (Year/s) (n=200).

\begin{tabular}{|c|c|c|}
\hline Duration & Frequency & Percentage \\
\hline$<1$ & 18 & 9 \\
\hline $1-4$ & 138 & 69 \\
\hline$>5$ & 44 & 22 \\
\hline
\end{tabular}

Table 3: Protective measures $(n=200)$.

\begin{tabular}{|c|c|c|}
\hline $\begin{array}{c}\text { Protective measures } \\
\text { (Boot, Gloves, Apron/jacket, } \\
\text { Googles, helmets and Sufficient water) }\end{array}$ & Frequency & Percentage \\
\hline Available or used & 56 & 28 \\
\hline Not Available or Not used & 144 & 72 \\
\hline
\end{tabular}

Table 4: Prevalence of diseases among construction workers $(\mathrm{n}=200)$.

\begin{tabular}{|c|c|c|}
\hline Disease & Frequency & Percentage \\
\hline Yes & 140 & 70 \\
\hline No & 60 & 30 \\
\hline
\end{tabular}

Table 5: Distribution of skin diseases among construction workers $(n=140)$.

\begin{tabular}{|c|c|c|}
\hline Disease & Frequency & Percentage \\
\hline Work place injuries & 40 & 28.6 \\
\hline Respiratory problems & 64 & 45.7 \\
\hline Occupational skin diseases & 110 & 78.6 \\
\hline Musculoskeletal disorders & 46 & 32.8 \\
\hline Others & 44 & 31.4 \\
\hline
\end{tabular}

\section{Discussion}

Rapid urbanization and industrialization have imposed a huge load of construction works worldwide, which creates different social, cultural and health impact. The construction workers are exposed to multiple risks at working and living places, they are exposed to physical, chemical, biological, ergonomic hazards and environmental and psycho social risks.

In the current study among two hundred construction workers $70 \%$ of them have at least one form of disease. Out of all skin diseases, were the most commonest (78.6\%) followed by respiratory problems $(45.7 \%)$ and musculoskeletal disorders $(32.8 \%)$.

Out of all skin diseases, 48 (40\%) patients were suffering from contact dermatitis, among which was irritant contact dermatitis (ICD) $26.7 \%$ and $13.3 \%$ allergic contact dermatitis (ACD). Other skin diseases were acne, seborrheic dermatitis, burn/scald accidental injury, scabies, fungal infection and palmoplantar keratoderma. The findings are consistent with the study conducted by Masqoor et al [1] and Sarwar et al [5].

In the current study only $28.0 \%$ workers had opportunity to use any form protective measure. The prolonged exposure to construction materials for years without almost no protective measures may be cause of this high rate of contact dermatitis. The construction workers are a group of less skilled workers who start the occupation without previous training; this situation facilitates the emergence of occupational dermatitis. More over in this study almost all workers are belong to low socio-economics class, they have limited excess to healthcare, lack of sufficient health education. All these factors produce a cumulative affect to their health which can be prevented by providing improved work place, protective means, health education, adequate health services and improving professional skills [5].

\section{Conclusion}

Measures are needed to improve the work environment of construction workers by ensuring availability of protective gears, good living conditions and sanitation facilities at the sites along with an accessible, accountable occupational health services. A system of health recording and routine surveillance among workers should be implemented. Local medical schools and occupational health institutes should be encouraged to study the health of construction workers in comparison with appropriate baseline control populations due to the significant deficiency of epidemiological data in this fast growing sector.

\section{Limitations}

a) The study was a cross-sectional study temporality, causation of the health outcomes were not proved and the actual incidence could not be recorded.

b) Those workers with severe morbidity may leave the job and due to the "healthy worker effect" the results may be an under reporting.

\section{References}

1. Ellenbecker T, Roetert P, Riewald S (2006) Iso kinetic profile of wrist and forearm strength in elite female junior tennis players. Br J Sports Med 40(5): 411-414. 
2. Gatt I, Smith-Moore S, Loosemore SCM (2017) The takei handheld dynamometer: an effective clinical outcome measure too for hand and wrist function in boxing. Hand.

3. Hagert E, Persson JKE, Werner M, Lyung BO (2009) Evidence of wrist proprioceptive reflexes elicited after stimulation of the scapholunate interosseous ligament. J Hand Surg Am 34(4): 642-651.

4. Hagert E, Forsgren S, Ljung BO (2005) Differences in the presence of mechanoreceptors and nerve structures between wrist ligaments may imply differential roles in wrist stabilization. J Orthop Res 23(4): 757763.

5. Loosemore M, Lightfoot J, PalmerGreen D, Gatt I (2017) Boxing injury epidemiology in the Great Britain team: a 5-year surveillance study of medically diagnosed injury incidence and outcome. British Journal of Sports Medicine 49(17): 11001107.

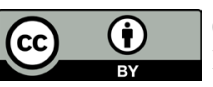

Creative Commons Attribution 4.0

International License

For possible submission use the below is the URL
6. Loosemore M, Lightfoot J, Gatt I, Hayton M, Beardsley C, et al. (2017) Hand and wrist injuries in elite boxing: A longitudinal prospective study (2005-2012) of the Great Britain Olympic boxing squad. Hand 12(2): 181-187.

7. Smith MS, Dyson RJ, Hale T, Janaway L (2000) Development of a boxing dynamometer and its punch force discrimination efficacy. J Sports Sci 18(6): 445-450.

8. Horst VDN, Backx FJG, Goedhart EA, Huisstede BMA (2017) Return to play after hamstring injuries in football (soccer): a worldwide Delphi procedure regarding definition, medical criteria and decision-making. Br J Sports Med 51(22): 1583-1591.

9. Vodicka T, Pieter W, Reguli Z, Zvonar M (2016) Iso kinetic strength of the wrist in male aikido athletes. Journal of Martial Arts Anthropology 16(2): 48-54.

\section{Your subsequent submission with Crimson Publishers will attain the below benefits}

- High-level peer review and editorial services

- Freely accessible online immediately upon publication

- Authors retain the copyright to their work

- Licensing it under a Creative Commons license

- Visibility through different online platforms

- Global attainment for your research

- Article availability in different formats (Pdf, E-pub, Full Text)

- Endless customer service

- Reasonable Membership services

- Reprints availability upon request

- One step article tracking system 